\title{
Recent Updates on Electro-Convulsive Therapy in Patients with Depression
}

\author{
Mi Jin Park', Hyewon Kim¹, Eun Ji Kim¹, Vidal Yook', \\ In Won Chung ${ }^{2}$, Sang Min Lee ${ }^{3}$, and Hong Jin Jeon ${ }^{1,4 凶}$ \\ 1Department of Psychiatry, Depression Center, Samsung Medical Center, Sungkyunkwan University School of Medicine, Seoul, Republic of Korea \\ 2Department of Psychiatry and Electroconvulsive Therapy Center, Dongguk University International Hospital, Goyang, Republic of Korea \\ ${ }^{3}$ Department of Psychiatry, School of Medicine, Kyung Hee University, Seoul, Republic of Korea \\ ${ }^{4}$ Department of Health Sciences \& Technology, Department of Medical Device Management \& Research, and Department of Clinical Research \\ Design \& Evaluation, Samsung Advanced Institute for Health Sciences \& Technology (SAIHST), Sungkyunkwan University, Seoul, Republic of Korea
}

Objective Electro-convulsive therapy (ECT) has been established as a treatment modality for patients with treatment-resistant depression and with some specific subtypes of depression. This narrative review intends to provide psychiatrists with the latest findings on the use of ECT in depression, devided into total eight sub-topics.

Methods We searched PubMed for English-language articles using combined keywords and tried to analyze journals published from 1995-2020.

Results Pharmacotherapy such as antidepressants or maintenance ECT is more effective than a placebo as prevention of recurrence after ECT. The use of ECT in treatment-resistant depression, depressed patients with suicidal risks, elderly depression, bipolar depression, psychotic depression, and depression during pregnancy or postpartum have therapeutic benefits. As possible mechanisms of ECT, the role of neurotransmitters such as serotonin, dopamine, gamma-aminobutyric acid (GABA), and other findings in the field of neurophysiology, neuro-immunology, and neurogenesis are also supported.

Conclusion ECT is evolving toward reducing cognitive side effects and maximizing therapeutic effects. If robust evidence for ECT through randomized controlled studies are more established and the mechanism of ECT gets further clarified, the scope of its use in the treatment of depression will be more expanded in the future.

Psychiatry Investig 2021;18(1):1-10

Key Words Electroconvulsive therapy, Depression, Suicide, Review.

\section{INTRODUCTION}

Electroconvulsive therapy (ECT) is considered as an effective therapeutic option for major depression with estimated response rates of $80-90 \%{ }^{1}$ The mortality rate was significantly lower in the ECT group compared to the inadequate antidepressant treatment group and non-treatment group. ${ }^{2}$ The

Received: September 18, 2020 Revised: November 1, 2020

Accepted: November 3, 2020

$\triangle$ Correspondence: Hong Jin Jeon, MD, PhD

Department of Psychiatry, Depression Center, Samsung Medical Center, Sungkyunkwan University School of Medicine, Seoul, Republic of Korea Department of Health Sciences \& Technology, Department of Medical Device Management \& Research, and Department of Clinical Research Design \& Evaluation, Samsung Advanced Institute for Health Sciences \& Technology (SAIHST), Sungkyunkwan University, 81 Irwon-ro, Gangnam-gu, Seoul 06351, Republic of Korea

Tel: +82-2-3410-3586, Fax: +82-2-3410-0050, E-mail: jeonhj@skku.edu

(c) This is an Open Access article distributed under the terms of the Creative Commons Attribution Non-Commercial License (https://creativecommons.org/licenses/bync/4.0) which permits unrestricted non-commercial use, distribution, and reproduction in any medium, provided the original work is properly cited.
ECT group also had significantly fewer suicide attempts than the antidepressant treatment group regardless of previous suicide attempts. ${ }^{3}$

A meta-analysis study included eighteen trials that compared ECT with drug therapy in depression and showed that ECT was significantly more effective than was pharmacotherapy, concluding that ECT can be an effective short-term treatment for depression. ${ }^{4}$ A report from the Consortium for Research in ECT (CORE) showed that optimized ECT results in a remission rate of $80 \%$ or more in severely depressed patients, though relapse seems to be frequent after the end of treatment. ${ }^{5}$ ECT has been suggested as preferential treatment for depression under specific presentations, such as postpartum depression, psychotic depression with or without catatonic features, and severe suicidal ideation or attempts. ${ }^{6}$

This review aims to provide psychiatrists with recent updates on ECT in patients with depression, focusing on eight sub-categories: maintenance therapy for preventing relapse 
after ECT; the efficacy of ECT in treatment-resistant depression; in depression with suicide risk; in geriatric depression; in bipolar depression; in psychotic depression; in pregnancy with depression or postpartum depression; and mechanism of ECT.

\section{METHOD}

We used the following search terms on PubMed: "Electroconvulsive" OR "ECT" or "Shock therapy" and "depression" OR "depressive disorder" OR "depress" with the addition of the term reviewed later according to the subcategories ("mechanism," "neurobiological," "neurophysiological," "relapse," "continuation," "maintenance," "pharmaco," "treatment resistant," "suicidal," "suicide," "elderly," "geriatric," "late-onset," "bipolar," "postpartum," "peripartum," "perinatal," "pregnancy"). The results of comparative studies are listed in Table 1.

\section{RESULT}

\section{Maintenance therapy for preventing relapse after ECT}

Continuation or maintenance ECT is widely accepted because of its effectiveness in preventing relapse or recurrence of depression. In a study from the CORE, continuation ECT (C-ECT) was compared with pharmacotherapy (C-Pharm) for preventing relapse after ECT in major depressive patients, of whom $37.1 \%$ experienced disease relapse in C-ECT and $31.6 \%$ in C-Pharm, with both groups showing better results than the placebo control. ${ }^{7}$ In a meta-analysis study, four C-ECT samples $(n=146)$ showed a $37.2 \%$ relapse rate at a six-month follow-up, with no significant difference from the relapse rate of $37.7 \%$ among modern-era pharmacologically treated patients. ${ }^{8}$ In a recent meta-analysis study that included five studies with 436 patients, continuation and maintenance ECT with pharmacotherapy showed fewer relapses and recurrences than did pharmacotherapy alone within a year after successful completion of ECT. ${ }^{9}$ A meta-analysis study reported that the relapse rate within one year following ECT exceeded 50\%, and when placebo only was given to the patients after the end of ECT, the relapse rate reached $84 \%{ }^{8,10}$ Although results from randomized controlled studies are needed for more rigorous evidence, maintenance ECT alone or combination with medication seems to be a reasonable treatment option for preventing relapse after ECT.

\section{ECT on treatment-resistant depression}

Treatment-resistant depression (TRD) is usually defined as depression that does not remit or respond to the use of two or more antidepressants for a sufficient period of time. ${ }^{11}$ The re- sponse rate to antidepressant treatment among patients with TRD is less than $17 \%$, but the response rate to ECT is reported to be between $50 \%$ and $60 \% .{ }^{12}$ When 39 subjects with TRD were randomized into the paroxetine treatment group or the ECT group, $75 \%$ of the patients in the ECT group satisfied the response criteria which is defined as least a $50 \%$ or more reduction of scores in Hamilton Depression Rating Scale (HAMD). ${ }^{1}$ The results from a naturalistic study that examined 38 severely depressed patients who received ECT demonstrated that the average of 5.4 medications failed before ECT, 65.8\% of the subjects responded to treatment after completion of ECT, and 53.3\% reached remission. ${ }^{13}$ In clinical guidelines established by the Canadian Psychiatric Association, ECT was recommended as a first-line treatment with evidence level 1 for $\mathrm{TRD}^{6}$ and the practice guidelines from Roya Australian and New Zealand College of Psychiatrists suggested ECT as an option for TRD early in the treatment algorithm. ${ }^{14}$ Magnetic seizure therapy (MST) was introduced as another type of convulsion therapy. MST is similar to ECT in that it causes generalized seizures, except that it uses high-frequency repetitive transcranial magnetic stimulation instead of direct electrical current. ${ }^{15}$ There is a growing body of evidence that recovery of orientation after MST is quick with limited cognitive side effects, ${ }^{16}$ but it needs to be compared with ECT in randomized condition to prove its efficacy in major mood disorder. ${ }^{17,18}$

\section{ECT on depression with suicide risk}

ECT is favored when an acute antidepressant effect is required, such as when treating major depressive disorder (MDD) accompanied by severe suicidality. ${ }^{19} \mathrm{~A}$ rapid reduction of suicidal ideations after ECT and repetitive transcranial magnetic stimulation has been reported in depressed patients. ${ }^{20}$

Limited clinical trial data exist on ECT's short-term or longterm effects on suicide risk. The uncontrolled studies provide evidence that ECT has an acute positive effect on suicide risk but there seems to be insufficient evidence for a long-term effect on suicide risk. ${ }^{19} \mathrm{~A}$ nationwide retrospective cohort study included in-patients with unipolar or bipolar disorder who completed ECT and were matched with controls with psychopharmacotherapy. The patients treated with ECT had $19.7 \%$ lower risk of suicide compared to those in the control group, showing the superior anti-suicidal effect of ECT. ${ }^{21}$ The 96 suicide victims with a primary severe depression were matched with the same number of controls from the same diagnosed sample of 1,206 patients. The suicide attempt rate was the lowest at $2 \%$ after ECT plus pharmacotherapy, $8 \%$ after ECT, and 20\% after sometimes receiving antidepressant pharmacotherapy. ${ }^{22}$

In a study of comparing continuous ECT and continuous pharmacotherapy, the expressed suicidal intent of the patients 


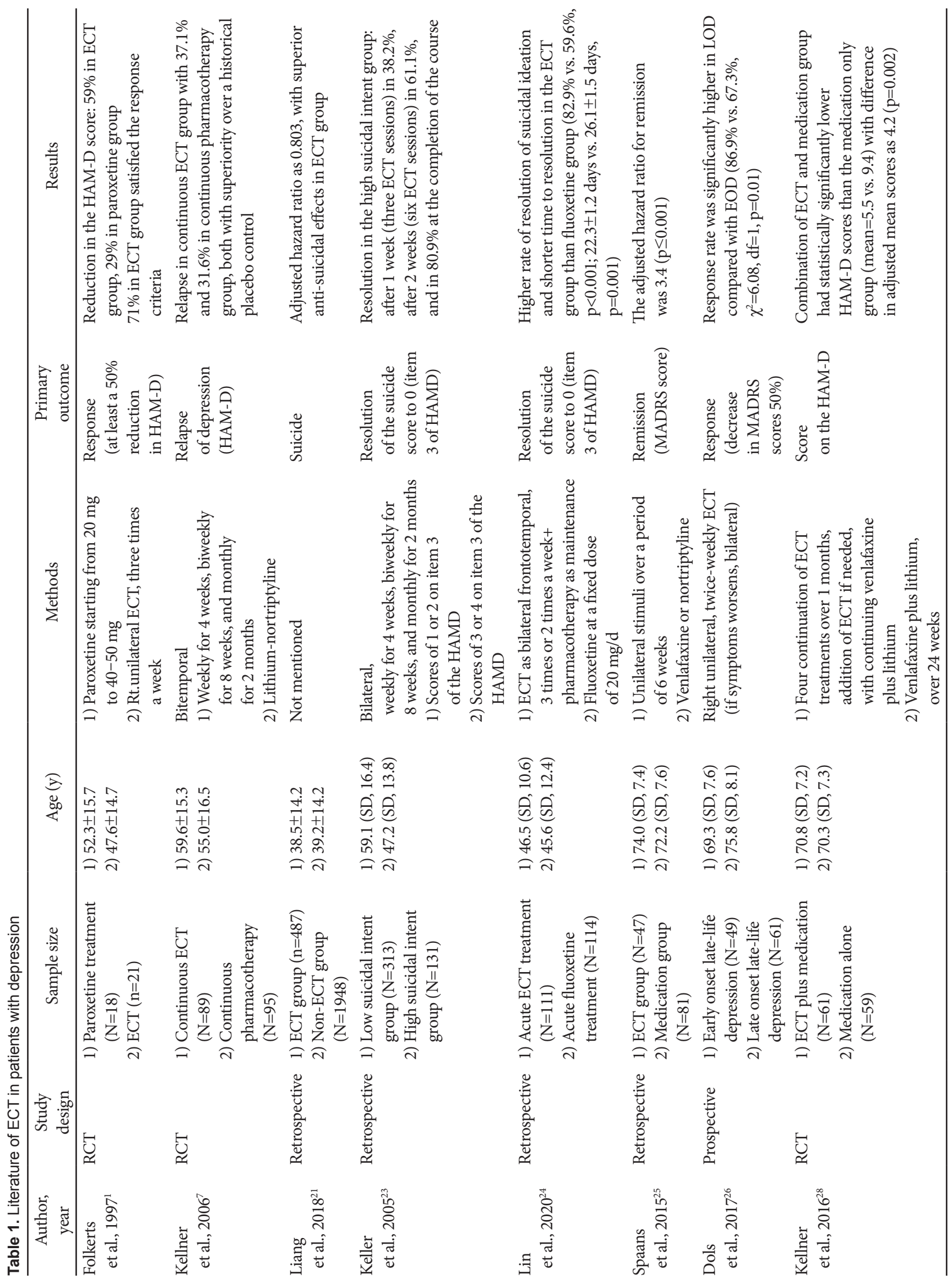




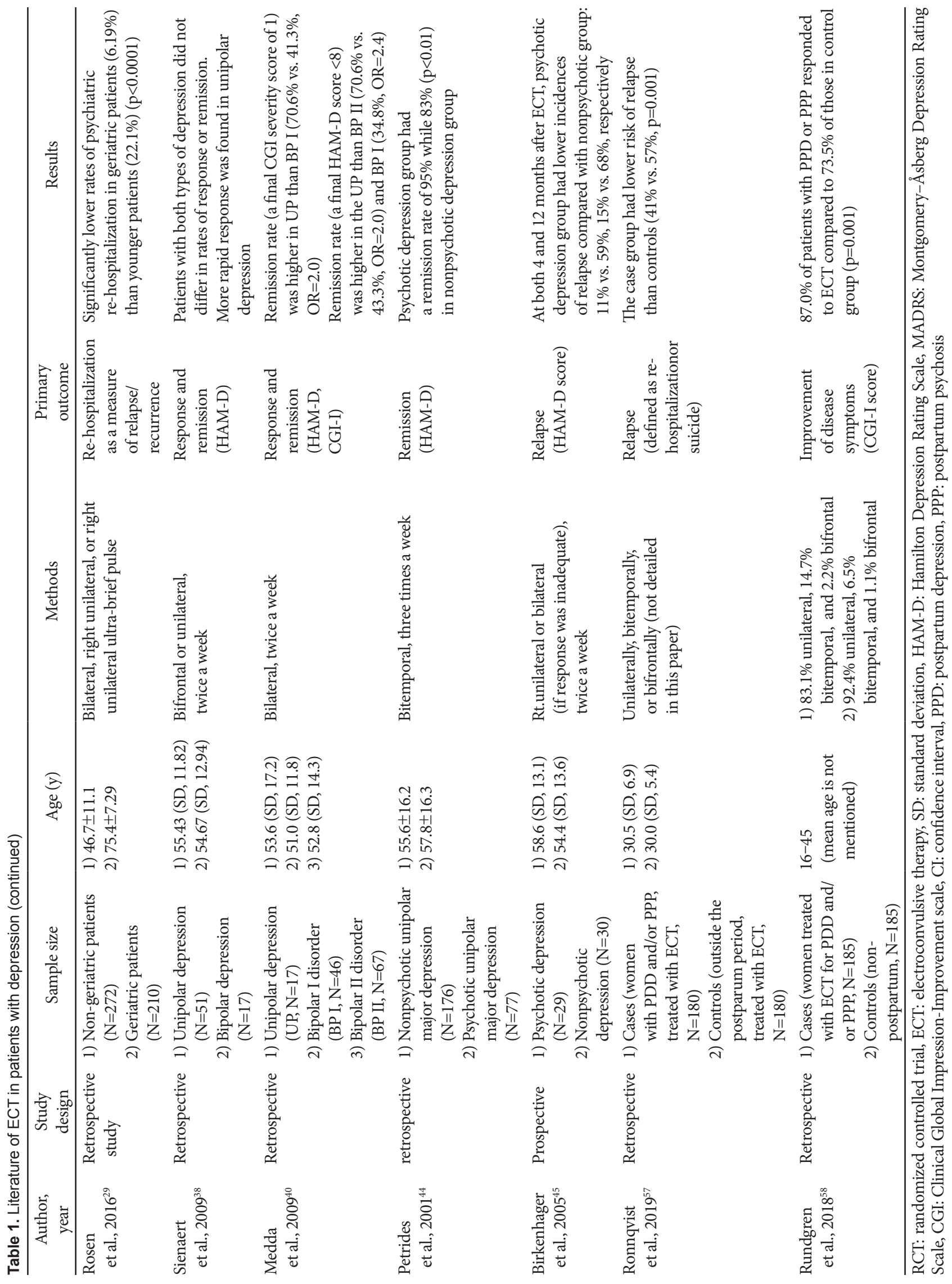


who received continuous ECT were evaluated based on the baseline suicidal intent score. In subjects with high suicidal intent [scores of 3 to 4 on item 3 of the Hamilton Depression Rating Scale (HAM-D)], 38.2\% showed a decrease in score to 0 after a week (three ECT sessions), $61.1 \%$ did after 2 weeks (six ECT sessions), and $80.9 \%$ did at the completion of all ECT sessions with rapid tranquilizing effect. ${ }^{23}$ In another comparison study on the efficacy of ECT on suicidal ideation, patients treated with ECT $(\mathrm{n}=111)$ had a significantly shorter time to alleviation of suicidal ideation than did patients treated with fluoxetine ( $\mathrm{n}=114)$ for acute treatment phase. In the three month follow-up period, no significant difference was found in the time to relapse of suicidal ideation between the two groups. ${ }^{24}$ The long-term efficacy of ECT on reducing suicidal ideation is unclear but it may be beneficial and even powerful for rapidly relieving suicidal ideation.

\section{Efficacy of ECT on geriatric depression}

Depressed elderly patients who received ECT had a mean time to remission of 3.1 weeks, which was earlier than 4.0 weeks of the medication treatment group, and had a significantly higher remission rate. ${ }^{25}$ Post ECT, patients with late onset $(\geq 55$ years) late-life depression showed a higher response rate of $86.9 \%$ compared to those with early onset ( $<55$ years) late-life depression who had response rate of $67.3 \%{ }^{26}$ Recently, the Prolonging Remission in Depressed Elderly (PRIDE) study investigated the efficacy of right unilateral ultra-brief pulse (R-UBP) ECT with venlafaxine for the treatment of geriatric depression in phase I; remitted patients were randomly assigned to receive six-month pharmacotherapy or pharmacotherapy plus ECT in phase 2. In phase I, $61.7 \%$ of the patients were remitted, $74.3 \%$ of the patients reached remission within 3 weeks (nine or fewer treatments), and $70 \%$ of the patients met remission criteria. ${ }^{27}$ In phase 2 , at six months, the ECT combined with medication (venlafaxine plus lithium) group showed statistically significantly lower HAM-D scores and rated more on "not ill at all" item on CGI-S than did the medication group. ${ }^{28}$ In terms of maintenance ECT, MDD patients (average age of 57) were randomly assigned to either a maintenance ECT group $(n=89)$ or continuous pharmacotherapy group $(n=95)$; Significant differences were not found in relapse rates and time to relapse between the two groups.?

When psychiatric re-hospitalization rates of geriatric patients were compared to those of non-geriatric patients after the end of ECT, geriatric patients achieved lower rates of psychiatric re-hospitalization than did non-geriatric patients (6.2\% vs. $22 \%){ }^{29}$ Based on the literature to date, maintenance ECT is well tolerated and seems as effective as continuation of medication after successful completion of ECT in elderly patients with severe depression. ${ }^{30}$ Despite concerns about negative ef- fects on cognitive functioning, such effects of ECT in geriatric depression were temporary and limited, with improved cognitive outcomes in unilateral ECT. ${ }^{31}$ The PRIDE that investigated the neurocognitive effects of ECT in elderly patients with MDD demonstrated only phonemic fluency, complex visual scanning, and cognitive flexibility were qualitatively decreased from low average to mildly impaired..$^{32}$ Also, the course of dementia is not deteriorated due to ECT and comorbidities such as depression or agitation are indications of ECT. ${ }^{33}$

\section{Bipolar depression and ECT}

Bipolar depression is known to have higher rates of medication nonresponse than that of unipolar depression, and the recurrence rate of a depressive episode is high, reaching $60 \%$ in the first 2 years and $75 \%$ in 5 years. ${ }^{34,35}$ In patients with bipolar disorder, more than $70 \%$ of suicide attempts and suicide deaths occur during depressed periods. ${ }^{6}$ Although ECT is usually sought as a last resort for bipolar depression, a metaanalysis study on the efficacy of ECT in bipolar depression report that response and remission rates of ECT in bipolar depression were not inferior to those in MDD. ${ }^{36}$

A register-based observational study included data of all patients with bipolar depression treated with ECT from 2011 to $2016 ; 80.2 \%$ of patients reached a response and older age was associated with a higher response rate. ${ }^{37}$ Efficacy and speed of response following ECT were compared between 51 unipolar and 13 bipolar depressive disorder patients. The results showed that the remission and response rates were not significantly different, but patients with unipolar depression presented a more rapid response. ${ }^{38}$ However, contrasting results also exist. In a retrospective study, patients with unipolar depression tended to show greater improvement than the patients with bipolar depression. ${ }^{39}$ When 17 patients with unipolar depression were compared with 113 patients with bipolar I or II disorder, the unipolar depression group showed a higher remission rate after ECT than either bipolar I or II disorder group. ${ }^{40}$

However, the efficacy of ECT in bipolar depression is supported by more study results. A meta-analysis study conducted for the purpose of identifying the relative efficacy of ECT in unipolar and bipolar depression, included six cohort studies and showed that the efficacy of ECT was similar in both types of depression $(\mathrm{OR}=1.08) .{ }^{41}$ Another systematic review and meta-analysis study reported similar results, which included nineteen articles; a similar remission rate was found in both MDD and bipolar depression patients, although a statistically higher response rate was documented in patients with bipolar depression. ${ }^{36}$

\section{Psychotic depression}

Psychotic depression is accompanied by psychotic symp- 
toms such as delusions or hallucinations. Epidemiological studies of psychotic disorder presented a prevalence of psychotic depression ranging from $0.35 \%$ to $1 \%$ and association with higher rate of recurrence, decreased quality of life, higher mortality rates, and higher risk of suicide. ${ }^{42,43}$

The expert opinions are inconsistent on the optimal treatment for psychotic depression, and the contents from nine international treatment guidelines are even contrasting. Five out of nine guidelines [the American Psychiatric Association (APA) 2010, Canadian Network for Mood and Anxiety Treatment (CANMAT) 2009, the Texas Medication Algorithm Project (TMAP) 2008, the Danish Board of Health (DNBH) 2007, the World Federation of Societies of Biological Psychiatry (WFSBP) 2020)] regard ECT as an equally appropriate first-line treatment for psychotic depression. ${ }^{42}$

Remission rate after application of ECT in psychotic unipolar depressed patients $(n=77)$ was compared to those in nonpsychotic depressed patients $(n=176)$. The overall remission rates assessed by change in scores of HAM-D were $87 \%$ in the patients who completed the study, $95 \%$ in the psychotic depression group, and $83 \%$ in the non-psychotic depression group, indicating that there was a robust and quicker improvement in psychotic patients. ${ }^{44}$ In 59 depressed patients ( 29 with psychotic features), the risk of relapse was prospectively assessed at one year after successful ECT. Patients with psychotic depression had significantly lower rates of relapse at one year and also at four months after the completion of ECT compared to non-psychotic patients. ${ }^{45}$ Although the evidences are limited, ECT appears to provide favorable outcomes to patients with psychotic depression.

\section{Depression in pregnancy and postpartum depression}

Depression is the most common mental disorder during pregnancy and it is estimated that approximately $9 \%$ of pregnant women suffer from an episode of MDD. ${ }^{46}$ As many as $50 \%$ of pregnant women get depressed after giving childbirth. ${ }^{47}$ In a study conducted among American women in 2005, $9.1 \%$ of pregnant women and $10.2 \%$ of postpartum women met diagnostic criteria for a major depressive episode. ${ }^{48} \mathrm{Al}$ though the evidences on effectiveness of ECT in pregnant women are mostly based on the results of case reports and there is no prospective controlled study, results from previous studies indicate that use of ECT is generally safe during the entire period of pregnancy. ${ }^{49,50}$ Maternal changes such as decreased utero-placental perfusion, risk of aspiration, compression on aortocaval system during pregnancy and other comorbidities and the possibility of fetal heart rate change may need to be considered, but serious adverse events caused by ECT during pregnancy seem to be uncommon. ${ }^{51}$
In a retrospective study, the efficacy and safety of ECT in 33 ( $n=19$ MDD; the rest=bipolar disorder or schizophrenia) pregnant patients were evaluated. In MDD patients, a complete response rate assessed by change in score of Clinical Global Impression-Severity scale (CGI-S) or HAM-D was $84.21 \%$ and a partial response rate was $15.78 \% .{ }^{52}$ In one case review of ECT in pregnancy from 1941 to 2007, the efficacy data were available in 68 out of 339 cases. In the 37 cases diagnosed with either MDD or depression, 26 reached remission and five reached partial remission, with overall $83.8 \%$ achieving at least partial remission. The risks of adverse events were low. ${ }^{53}$ Significant adverse outcomes were not reported except one case of early childbirth and pes ekinovarus deformity in a newborn which was most probably not associated with ECT. ${ }^{54}$ Given current knowledge, although there may be some fetal complications such as self-limiting fetal cardiac arrhythmia, or early delivery and maternal complications such as vaginal bleeding, uterine contraction, abdominal pain, or changes in blood pressure, those complications are generally mild and curable. ${ }^{55}$ Therefore, ECT is relatively safe and effective as an alternative treatment option for depression during pregnancy.

180 patients with postpartum depression and/or postpartum psychosis ( 0.25 to 0.6 per 1,000 deliveries, with manic, mixed or psychotic symptoms $)^{56}$ received ECT within six months after delivery and were compared to the same number of depressed patients that received ECT and were not in postpartum period. Percentages of patients who experienced relapse after 6 months, 1 year, and 2 years were lower in the postpartum group than those in the control group. ${ }^{57}$ In another population-based study, improvement of postpartum depression and psychosis after ECT was compared to that in a matched comparison group (not within the postpartum period). 185 subjects were included in each group, and improvement at one week after ECT was evaluated using the Clinical Global Impression-Improvement scale (CGI-I). The postpartum group responded more to ECT at $87.0 \%$ than did the comparison group at $73.5 \% .{ }^{58}$ In one systematic review and case report, eight cases and eight studies were included. Although most of the patients were diagnosed with postpartum psychosis, all studies concluded that ECT is effective in the postpartum period with strength of good tolerability, fast response, and allowance for breastfeeding. ${ }^{59}$

\section{The neurobiological mechanism of ECT}

Gamma-Aminobutyric acid (GABA) has been suggested to mediate anticonvulsant effect of ECT, supported by rise in seizure threshold during the course of ECT. ${ }^{60} \mathrm{GABA}_{\mathrm{A}}$ receptor mRNA in the hippocampus and cerebellum, $\mathrm{GABA}_{B}$ binding in rat brain after repeated electroconvulsive seizures (ECS, an analogue of ECT in animal model), GABA concentration 
in the occipital cortex were increased. ${ }^{61-64}$ Because elevated glutamate levels were found in the different brain areas of depressed patient, ${ }^{65}$ a glutamate-normalizing action of ECT has been suggested. ${ }^{66}$

ECT seems to be associated with transiently increased dopamine receptor binding and neurotransmission, ${ }^{67}$ decreased a2-adrenoceptor as a result of sustained release of noradrenaline ${ }^{68}$ increased expression of neuropeptide Y (NPY) mRNA and peptide release in cortex as well as hippocampus, and increase of thyrotropin-releasing hormone (TRH). ${ }^{69}$ Like antidepressants, ECT seems to reduce and further down-regulate 5$\mathrm{HT}_{2}$ receptors in the brain ${ }^{70}$ but the findings are inconsistent. ${ }^{71,72}$

Relationship between the activated immune system and the effects of ECT is supported by temporarily increased expression of inflammatory cytokine genes (such as IL-beta, IL-6) ${ }^{73}$ and normalization of high cortisol levels which are associated with inhibition of neurogenesis, gliogenesis, and atrophy of structures such as hippocampus. ${ }^{74}$ However, chronic application of ECT shows decreased immune system activity. ${ }^{75}$

In terms of neurophysiological change, an increase in regional cerebral blood flow is observed in the brain during a seizure. ${ }^{76}$ During ECT or immediately after ECT, regional differences in blood flow were also documented. ${ }^{77}$ After ECT, metabolism decreased in the frontotemporal neo-cortical areas while it increased in the right medial temporal structures including amygdala and pons, ${ }^{78}$ though research findings on post-ECT reduction in absolute levels of blood flow are inconsistent. $^{76,79}$

ECT also transiently increases the permeability of the bloodbrain barrier and generates changes such as increase of neurotrophic factor, angiogenesis, and neurogenesis after multiple applications of ECS. ${ }^{80}$ Brain-derived neurotrophic factor (BDNF), known as a nerve-growth factor that mediates neuronal growth, proliferation, repair, and survival, has been widely studied for understanding the therapeutic effects of ECT and has proved to be increased after ECT. ${ }^{81,82}$ Expression of vascular endothelial growth factor (VEGF), glial cell-line derived neurotrophic factor (GDNF) and basic fibroblast growth factor-2 (FGF-2) seems to be increased after ECT or ECS. ${ }^{83-85}$

In a model of psychosis in mice, ECS seems to resemble atypical antipsychotics with differential effects on dopaminergic pathways ${ }^{86}$ and neurodevelopmental hypothesis is supported with increased neuroprotective molecules such as BDNF and proliferation of hippocampal progenitor cells. ${ }^{87}$ Compared with depression, immune system and inflammation hypothesis of psychosis is not clear with few study results.

\section{DISCUSSION}

ECT has been in use since the 1920s, but its use has been de- clining for some time because of negative perceptions and antipsychotic drugs were introduced one after another. During the ECT procedure, there can be cardiovascular changes such as increased blood pressure, increased heart rate or arrhythmia, anesthetic side effects such as aspiration and respiratory suppression, and musculoskeletal side effects, but safety is increasing due to improvement of ECT technique and anesthesia technique. ${ }^{88}$ As psychiatric side effects, temporary disorientation and postictal delirium may occur, and may be accompanied by anterograde or retrograde amnesia, but usually temporary and recovers over time. ${ }^{89}$ Recently, it is evolving toward reducing cognitive side effects and maximizing therapeutic effects. During the ECT procedure, the location of the electrode and the physical properties of the stimulation influence the seizure threshold, which is related to the therapeutic effect and cognitive adverse effects. Generally, right unilateral ECT gets less severe cognitive impairment than bilateral ECT but needs a high dose (6 times seizure threshold) for the efficacy of treatment. ${ }^{4}$ Relative high dose compared to bilateral ECT (1.5-2.5 times threshold) can offsets the advantage of unilateral ECT. ${ }^{90}$ Clinical data on the use of bifrontal ECT have suggested fewer cognitive adverse effects, but more evidence is needed to prove its superiority over bilateral ECT. ${ }^{91}$ Theoretically, ultra-brief pulse width (0.3-0.5 miliseconds), lower pulse frequency and longer duration generates seizure with a small amount of charge. Ultra-brief pulse width unilateral ECT or bifrontal ECT has shown to be effective with cognitive preserving. ${ }^{92,93}$ In addition to this, new methods such as magnetic seizure therapy or focal electrically administered seizure therapy, which can avoid cognitive impairment by inducing local convulsions, are also being tried..$^{90}$ The use of antidepressant during ECT may also affects seizure properties. Fluoxetine and mirtazapine are known to increase seizure duration and venlafaxine relatively decrease. Therapeutic effectiveness seems to be enhanced when combined with tricyclics, selective serotonin reuptake inhibitors (SSRIs) or mirtazapine. Although SSRIs may induce serotonin syndrome, most side effects were not serious and temporary. ${ }^{94}$

As a mechanism of ECT, changes in neurotransmitters and hormones, changes in the physicochemical environment in the brain, and neuroplastic neuronal generation have been reported, but the link between the various research results is still unclear. ${ }^{95}$ More evidence points towards using antidepressants after ECT to prevent recurrence, however maintenance ECT may have the same effect as drugs. In depressed patients with suicide risk, ECT has acute, and rapid tranquilizing effects. The use of ECT for depression in the elderly showed rapid treatment response and high remission rate, and was effective as maintenance antidepressant treatment to prevent recurrence. The effect of ECT in bipolar depression was not in- 
ferior to that in unipolar depression. Although the data are limited, patients with psychotic depression seem to show rapid response and low relapse rate when treated with ECT. The use of ECT in depression during pregnancy or after childbirth is effective in terms of treatment response, maintenance of remission, and safety. It is necessary to establish robust evidence for ECT through randomized controlled studies, and if the mechanism of ECT gets further clarified, the scope of its use in the treatment environment of depression will be expanded in the future.

\section{Acknowledgments}

This research was supported by the Original Technology Research Program for Brain Science through the National Research Foundation of Korea (NRF) funded by the Ministry of Education, Science and Technology (No. NRF-2016M3C7A1947307; PI HJJ), by the Bio \& Medical Technology Development Program of the NRF funded by the Korean government, MSIT (No. NRF-2017M3A9F1027323; PI HJJ), and by Healthcare AI Convergence Research \& Development Program through the National IT Industry Promotion Agency of Korea (NIPA) funded by the Ministry of Science and ICT (No. S1601-20-1041).

\section{Conflicts of Interest}

The authors have no potential conflicts of interest to disclose.

\section{Author Contributions}

Conceptualization: Hong Jin Jeon. Investigation: all authors. Writingoriginal draft: Mi Jin Park, Hong Jin Jeon. Writing_review \& editing: all authors.

\section{ORCID iDs}

$\begin{array}{ll}\text { Mi Jin Park } & \text { https://orcid.org/0000-0002-3620-1192 } \\ \text { Hyewon Kim } & \text { https://orcid.org/0000-0001-5665-8280 } \\ \text { Eun Ji Kim } & \text { https://orcid.org/0000-0001-6597-1236 } \\ \text { Vidal Yook } & \text { https://orcid.org/0000-0003-2410-1706 } \\ \text { In Won Chung } & \text { https://orcid.org/0000-0001-9894-7005 } \\ \text { Sang Min Lee } & \text { https://orcid.org/0000-0002-7834-8272 } \\ \text { Hong Jin Jeon } & \text { https://orcid.org/0000-0002-6126-542X }\end{array}$

\section{REFERENCES}

1. Folkerts HW, Michael N, Tolle R, Schonauer K, Mucke S, SchulzeMonking H. Electroconvulsive therapy vs. paroxetine in treatment-resistant depression- a randomized study. Acta Psychiatr Scand 1997;96: 334-342.

2. Avery D, Winokur G. Mortality in depressed patients treated with electroconvulsive therapy and antidepressants. Arch Gen Psychiatry 1976; 33:1029-1037.

3. Avery D, Winokur G. Suicide, attempted suicide, and relapse rates in depression. Arch Gen Psychiatry 1978;35:749-753.

4. Group UER. Efficacy and safety of electroconvulsive therapy in depressive disorders: a systematic review and meta-analysis. Lancet 2003;361: 799-808.

5. Fink M. What was learned: studies by the consortium for research in ECT (CORE) 1997-2011. Acta Psychiatr Scand 2014;129:417-426.

6. Yatham LN, Kennedy SH, Parikh SV, Schaffer A, Bond DJ, Frey BN, et al. Canadian Network for Mood and Anxiety Treatments (CANMAT) and International Society for Bipolar Disorders (ISBD) 2018 guidelines for the management of patients with bipolar disorder. Bipolar Disord 2018;20:97-170

7. Kellner CH, Knapp RG, Petrides G, Rummans TA, Husain MM, Ras- mussen $\mathrm{K}$, et al. Continuation electroconvulsive therapy vs pharmacotherapy for relapse prevention in major depression: a multisite study from the Consortium for Research in Electroconvulsive Therapy (CORE). Arch Gen Psychiatry 2006;63:1337-1344.

8. Jelovac A, Kolshus E, McLoughlin DM. Relapse following successful electroconvulsive therapy for major depression: a meta-analysis. Neuropsychopharmacology 2013;38:2467-2474.

9. Elias A, Phutane VH, Clarke S, Prudic J. Electroconvulsive therapy in the continuation and maintenance treatment of depression: systematic review and meta-analyses. Aust N Z J Psychiatry 2018;52:415-424.

10. Sackeim HA, Haskett RF, Mulsant BH, Thase ME, Mann JJ, Pettinati $\mathrm{HM}$, et al. Continuation pharmacotherapy in the prevention of relapse following electroconvulsive therapy: a randomized controlled trial. JAMA 2001;285:1299-1307.

11. Malhi GS, Parker GB, Crawford J, Wilhelm K, Mitchell PB. Treatmentresistant depression: resistant to definition? Acta Psychiatr Scand 2005; 112:302-309.

12. Greenberg RM, Kellner CH. Electroconvulsive therapy: a selected review. Am J Geriatr Psychiatry 2005;13:268-281.

13. Khalid N, Atkins M, Tredget J, Giles M, Champney-Smith K, Kirov G. The effectiveness of electroconvulsive therapy in treatment-resistant depression: a naturalistic study. J ECT 2008;24:141-145.

14. Malhi GS, Bassett D, Boyce P, Bryant R, Fitzgerald PB, Fritz K, et al. Royal Australian and New Zealand College of Psychiatrists clinical practice guidelines for mood disorders. Aust N Z J Psychiatry 2015;49:1087-1206.

15. Hoy KE, Fitzgerald PB. Magnetic seizure therapy for treatment-resistant depression. Expert Rev Med Devices 2011;8:723-732.

16. Lisanby SH, Luber B, Schlaepfer TE, Sackeim HA. Safety and feasibility of magnetic seizure therapy (MST) in major depression: randomized within-subject comparison with electroconvulsive therapy. Neuropsychopharmacology 2003;28:1852-1865.

17. Daskalakis ZJ, Dimitrova J, McClintock SM, Sun Y, Voineskos D, Rajji TK, et al. Magnetic seizure therapy (MST) for major depressive disorder. Neuropsychopharmacology 2020;45:276-282.

18. Lisanby SH. Update on magnetic seizure therapy: a novel form of convulsive therapy. J ECT 2002;18:182-188.

19. Sharma V. The effect of electroconvulsive therapy on suicide risk in patients with mood disorders. Can J Psychiatry 2001;46:704-709.

20. Courtet, Philippe (Ed.). Understanding Suicide from Diagnosis to Personalized Treatment. Switzerland: Springer; 2016.

21. Liang CS, Chung CH, Ho PS, Tsai CK, Chien WC. Superior anti-suicidal effects of electroconvulsive therapy in unipolar disorder and bipolar depression. Bipolar Disord 2018;20:539-546.

22. Bradvik L, Berglund M. Long-term treatment and suicidal behavior in severe depression: ECT and antidepressant pharmacotherapy may have different effects on the occurrence and seriousness of suicide attempts. Depress Anxiety 2006;23:34-41.

23. Kellner CH, Fink M, Knapp R, Petrides G, Husain M, Rummans T, et al. Relief of expressed suicidal intent by ECT: a consortium for research in ECT study. Am J Psychiatry 2005;162:977-982.

24. Lin CH, Chen CC, Huang CJ. Electroconvulsive therapy versus fluoxetine in suicidal resolution for patients with major depressive disorder. J ECT 2020;36:234-241.

25. Spaans HP, Sienaert P, Bouckaert F, van den Berg JF, Verwijk E, Kho $\mathrm{KH}$, et al. Speed of remission in elderly patients with depression: electroconvulsive therapy v. medication. Br J Psychiatry 2015;206:67-71.

26. Dols A, Bouckaert F, Sienaert P, Rhebergen D, Vansteelandt K, Ten Kate $\mathrm{M}$, et al. Early- and late-onset depression in late life: a prospective study on clinical and structural brain characteristics and response to electroconvulsive rherapy. Am J Geriatr Psychiatry 2017;25:178-189.

27. Kellner CH, Husain MM, Knapp RG, McCall WV, Petrides G, Rudorfer MV, et al. Right unilateral ultrabrief pulse ECT in geriatric depression: phase 1 of the PRIDE study. Am J Psychiatry 2016;173:1101-1109.

28. Kellner CH, Husain MM, Knapp RG, McCall WV, Petrides G, Rudorfer MV, et al. A novel strategy for continuation ECT in geriatric depres- 
sion: phase 2 of the PRIDE study. Am J Psychiatry 2016;173:1110-1118.

29. Rosen BH, Kung S, Lapid MI. Effect of age on psychiatric rehospitalization rates after electroconvulsive therapy for patients with depression. J ECT 2016;32:93-98.

30. van Schaik AM, Comijs HC, Sonnenberg CM, Beekman AT, Sienaert P, Stek ML. Efficacy and safety of continuation and maintenance electroconvulsive therapy in depressed elderly patients: a systematic review. Am J Geriatr Psychiatry 2012;20:5-17.

31. Kumar S, Mulsant BH, Liu AY, Blumberger DM, Daskalakis ZJ, Rajji TK. Systematic review of cognitive effects of electroconvulsive therapy in late-life depression. Am J Geriatr Psychiatry 2016;24:547-565.

32. Lisanby SH, McClintock SM, Alexopoulos G, Bailine SH, Bernhardt E, Briggs MC, et al. Neurocognitive effects of combined Electroconvulsive Therapy (ECT) and venlafaxine in geriatric depression: Phase 1 of the PRIDE study. Am J Geriatr Psychiatry 2020;28:304-316.

33. Meyer JP, Swetter SK, Kellner CH. Electroconvulsive therapy in geriatric psychiatry: a selective review. Clin Geriatr Med 2020;36:265-279.

34. Najafi-Vosough R, Ghaleiha A, Faradmal J, Mahjub H. Recurrence in patients with bipolar disorder and its risk factors. Iran J Psychiatry 2016; 11:173-177.

35. Vazquez G, Tondo L, Baldessarini RJ. Comparison of antidepressant responses in patients with bipolar vs. unipolar depression: a meta-analytic review. Pharmacopsychiatry 2011;44:21-26.

36. Bahji A, Hawken ER, Sepehry AA, Cabrera CA, Vazquez G. ECT beyond unipolar major depression: systematic review and meta-analysis of electroconvulsive therapy in bipolar depression. Acta Psychiatr Scand 2019;139:214-226.

37. Popiolek K, Bejerot S, Brus O, Hammar A, Landen M, Lundberg J, et al. Electroconvulsive therapy in bipolar depression-effectiveness and prognostic factors. Acta Psychiatr Scand 2019;140:196-204.

38. Sienaert P, Vansteelandt K, Demyttenaere K, Peuskens J. Ultra-brief pulse ECT in bipolar and unipolar depressive disorder: differences in speed of response. Bipolar Disord 2009;11:418-424.

39. Homan S, Lachenbruch PA, Winokur G, Clayton P. An efficacy study of electroconvulsive therapy and antidepressants in the treatment of primary depression. Psychol Med 1982;12:615-624.

40. Medda P, Perugi G, Zanello S, Ciuffa M, Cassano GB. Response to ECT in bipolar I, bipolar II and unipolar depression. J Affect Disord 2009;118: 55-59.

41. Dierckx B, Heijnen WT, van den Broek WW, Birkenhager TK. Efficacy of electroconvulsive therapy in bipolar versus unipolar major depression: a meta-analysis. Bipolar Disord 2012;14:146-150.

42. Leadholm AK, Rothschild AJ, Nolen WA, Bech P, Munk-Jorgensen P, Ostergaard SD. The treatment of psychotic depression: is there consensus among guidelines and psychiatrists? J Affect Disord 2013;145:214220.

43. Gournellis R, Tournikioti K, Touloumi G, Thomadakis C, Michalopoulou PG, Michopoulos I, et al. Psychotic (delusional) depression and completed suicide: a systematic review and meta-analysis. Ann Gen Psychiatry 2018;17:39.

44. Petrides G, Fink M, Husain MM, Knapp RG, Rush AJ, Mueller M, et al. ECT remission rates in psychotic versus nonpsychotic depressed patients: a report from CORE. J ECT 2001;17:244-253.

45. Birkenhager TK, van den Broek WW, Mulder PG, de Lely A. One-year outcome of psychotic depression after successful electroconvulsive therapy. J ECT 2005;21:221-226.

46. Wisner KL, Gelenberg AJ, Leonard H, Zarin D, Frank E. Pharmacologic treatment of depression during pregnancy. JAMA 1999;282:12641269.

47. Dietz PM, Williams SB, Callaghan WM, Bachman DJ, Whitlock EP, Hornbrook MC. Clinically identified maternal depression before, during, and after pregnancies ending in live births. Am J Psychiatry 2007; 164:1515-1520.

48. Hoertel N, Lopez S, Peyre H, Wall MM, Gonzalez-Pinto A, Limosin F, et al. Are symptom features of depression during pregnancy, the post- partum period and outside the peripartum period distinct? Results from a nationally representative sample using item response theory (IRT). Depress Anxiety 2015;32:129-140.

49. Ray-Griffith SL, Coker JL, Rabie N, Eads LA, Golden KJ, Stowe ZN. Pregnancy and electroconvulsive therapy: a multidisciplinary approach. J ECT 2016;32:104-112.

50. Rasmussen $\mathrm{K}$. The practice of electroconvulsive therapy: recommendations for treatment, training, and privileging (second edition). J ECT 2002; 18:58-59.

51. Rose S, Dotters-Katz SK, Kuller JA. Electroconvulsive therapy in pregnancy: safety, best practices, and barriers to care. Obstet Gynecol Surv 2020;75:199-203.

52. Bulbul F, Copoglu US, Alpak G, Unal A, Demir B, Tastan MF, et al. Electroconvulsive therapy in pregnant patients. Gen Hosp Psychiatry 2013; 35:636-639.

53. Anderson EL, Reti IM. ECT in pregnancy: a review of the literature from 1941 to 2007. Psychosom Med 2009;71:235-242.

54. Bulut M, Bez Y, Kaya MC, Copoglu US, Bulbul F, Savas HA. Electroconvulsive therapy for mood disorders in pregnancy. J ECT 2013;29:e19e20.

55. Pompili M, Dominici G, Giordano G, Longo L, Serafini G, Lester D, et al. Electroconvulsive treatment during pregnancy: a systematic review. Expert Rev Neurother 2014;14:1377-1390.

56. Bergink V, Rasgon N, Wisner KL. Postpartum psychosis: madness, mania, and melancholia in motherhood. Am J Psychiatry 2016;173:11791188.

57. Ronnqvist I, Brus O, Hammar A, Landen M, Lundberg J, Nordanskog $\mathrm{P}$, et al. Rehospitalization of postpartum depression and psychosis after electroconvulsive therapy: a population-based study with a matched control group. J ECT 2019;35:264-271.

58. Rundgren S, Brus O, Bave U, Landen M, Lundberg J, Nordanskog P, et al. Improvement of postpartum depression and psychosis after electroconvulsive therapy: a population-based study with a matched comparison group. J Affect Disord 2018;235:258-264.

59. Gressier F, Rotenberg S, Cazas O, Hardy P. Postpartum electroconvulsive therapy: a systematic review and case report. Gen Hosp Psychiatry 2015;37:310-314.

60. Duthie AC, Perrin JS, Bennett DM, Currie J, Reid IC. Anticonvulsant mechanisms of electroconvulsive therapy and relation to therapeutic efficacy. J ECT 2015;31:173-178.

61. Kang I, Miller LG, Moises J, Bazan NG. GABAA receptor mRNAs are increased after electroconvulsive shock. Psychopharmacol Bull 1991; 27:359-363.

62. Brambilla P, Perez J, Barale F, Schettini G, Soares JC. GABAergic dysfunction in mood disorders. Mol Psychiatry 2003;8:721-737, 715.

63. Knudsen MK, Near J, Blicher AB, Videbech P, Blicher JU. Magnetic resonance (MR) spectroscopic measurement of gamma-aminobutyric acid (GABA) in major depression before and after electroconvulsive therapy. Acta Neuropsychiatr 2019;31:17-26.

64. Sanacora G, Mason GF, Rothman DL, Hyder F, Ciarcia JJ, Ostroff RB, et al. Increased cortical GABA concentrations in depressed patients receiving ECT. Am J Psychiatry 2003;160:577-579.

65. Grimm S, Luborzewski A, Schubert F, Merkl A, Kronenberg G, Colla $\mathrm{M}$, et al. Region-specific glutamate changes in patients with unipolar depression. J Psychiatr Res 2012;46:1059-1065.

66. Njau S, Joshi SH, Espinoza R, Leaver AM, Vasavada M, Marquina A, et al. Neurochemical correlates of rapid treatment response to electroconvulsive therapy in patients with major depression. J Psychiatry Neurosci 2017;42:6-16.

67. Landau AM, Chakravarty MM, Clark CM, Zis AP, Doudet DJ. Electroconvulsive therapy alters dopamine signaling in the striatum of non-human primates. Neuropsychopharmacology 2011;36:511-518.

68. Lillethorup TP, Iversen P, Fontain J, Wegener G, Doudet DJ, Landau AM. Electroconvulsive shocks decrease alpha2-adrenoceptor binding in the Flinders rat model of depression. Eur Neuropsychopharmacol 
2015;25:404-412.

69. Altar CA, Laeng P, Jurata LW, Brockman JA, Lemire A, Bullard J, et al. Electroconvulsive seizures regulate gene expression of distinct neurotrophic signaling pathways. J Neurosci 2004;24:2667-2677.

70. Yatham LN, Liddle PF, Lam RW, Zis AP, Stoessl AJ, Sossi V, et al. Effect of electroconvulsive therapy on brain 5-HT(2) receptors in major depression. Br J Psychiatry 2010;196:474-479.

71. Lanzenberger R, Baldinger P, Hahn A, Ungersboeck J, Mitterhauser M, Winkler D, et al. Global decrease of serotonin-1A receptor binding after electroconvulsive therapy in major depression measured by PET. Mol Psychiatry 2013;18:93-100.

72. Saijo T, Takano A, Suhara T, Arakawa R, Okumura M, Ichimiya T, et al. Effect of electroconvulsive therapy on 5-HT1A receptor binding in patients with depression: a PET study with [11C]WAY 100635. Int J Neuropsychopharmacol 2010;13:785-791.

73. Lehtimaki K, Keranen T, Huuhka M, Palmio J, Hurme M, Leinonen E, et al. Increase in plasma proinflammatory cytokines after electroconvulsive therapy in patients with depressive disorder. J ECT 2008;24:8891.

74. O’Brien JT, Lloyd A, McKeith I, Gholkar A, Ferrier N. A longitudinal study of hippocampal volume, cortisol levels, and cognition in older depressed subjects. Am J Psychiatry 2004;161:2081-2090.

75. Yrondi A, Sporer M, Peran P, Schmitt L, Arbus C, Sauvaget A. Electroconvulsive therapy, depression, the immune system and inflammation: a systematic review. Brain Stimul 2018;11:29-51.

76. Takano H, Motohashi N, Uema T, Ogawa K, Ohnishi T, Nishikawa M, et al. Differences in cerebral blood flow between missed and generalized seizures with electroconvulsive therapy: a positron emission tomographic study. Epilepsy Res 2011;97:225-228.

77. Takano H, Motohashi N, Uema T, Ogawa K, Ohnishi T, Nishikawa M, et al. Changes in regional cerebral blood flow during acute electroconvulsive therapy in patients with depression: positron emission tomographic study. Br J Psychiatry 2007;190:63-68.

78. Suwa T, Namiki C, Takaya S, Oshita A, Ishizu K, Fukuyama H, et al. Corticolimbic balance shift of regional glucose metabolism in depressed patients treated with ECT. J Affect Disord 2012;136:1039-1046.

79. Berggren A, Gustafson L, Hoglund P, Johanson A. A long-term followup of clinical response and regional cerebral blood flow changes in depressed patients treated with ECT. J Affect Disord 2014;167:235-243.

80. Andrade C, Bolwig TG. Electroconvulsive therapy, hypertensive surge, blood-brain barrier breach, and amnesia: exploring the evidence for a connection. J ECT 2014;30:160-164.

81. Luan S, Zhou B, Wu Q, Wan H, Li H. Brain-derived neurotrophic factor blood levels after electroconvulsive therapy in patients with major depressive disorder: a systematic review and meta-analysis. Asian J Psychiatr 2020;51:101983.

82. Brunoni AR, Baeken C, Machado-Vieira R, Gattaz WF, Vanderhasselt
MA. BDNF blood levels after electroconvulsive therapy in patients with mood disorders: a systematic review and meta-analysis. World J Biol Psychiatry 2014;15:411-418.

83. Maffioletti E, Gennarelli M, Magri C, Bocchio-Chiavetto L, Bortolomasi M, Bonvicini C, et al. Genetic determinants of circulating VEGF levels in major depressive disorder and electroconvulsive therapy response. Drug Dev Res 2020;81:593-599.

84. Zhang X, Zhang Z, Sha W, Xie C, Xi G, Zhou H, et al. Electroconvulsive therapy increases glial cell-line derived neurotrophic factor (GDNF) serum levels in patients with drug-resistant depression. Psychiatry Res 2009; 170:273-275.

85. Kondratyev A, Ved R, Gale K. The effects of repeated minimal electroconvulsive shock exposure on levels of mRNA encoding fibroblast growth factor-2 and nerve growth factor in limbic regions. Neuroscience 2002;114:411-416.

86. Chao YL, Chen $\mathrm{HH}$, Chen $\mathrm{CH}$. Effects of repeated electroconvulsive shock on methamphetamine-induced behavioral abnormalities in mice. Brain Stimul 2012;5:393-401.

87. Newton SS, Collier EF, Hunsberger J, Adams D, Terwilliger R, Selvanayagam E, et al. Gene profile of electroconvulsive seizures: induction of neurotrophic and angiogenic factors. J Neurosci 2003;23:10841-10851.

88. Nuttall GA, Bowersox MR, Douglass SB, McDonald J, Rasmussen LJ, Decker PA, et al. Morbidity and mortality in the use of electroconvulsive therapy. J ECT 2004;20:237-241.

89. Semkovska M, McLoughlin DM. Objective cognitive performance associated with electroconvulsive therapy for depression: a systematic review and meta-analysis. Biol Psychiatry 2010;68:568-577.

90. Loo CK, Schweitzer I, Pratt C. Recent advances in optimizing electroconvulsive therapy. Aust N Z J Psychiatry 2006;40:632-638.

91. Hermida AP, Glass OM, Shafi H, McDonald WM. Electroconvulsive therapy in depression: current practice and future direction. Psychiatr Clin North Am 2018;41:341-353.

92. Sienaert P, Vansteelandt K, Demyttenaere K, Peuskens J. Randomized comparison of ultra-brief bifrontal and unilateral electroconvulsive therapy for major depression: clinical efficacy. J Affect Disord 2009;116: 106-112.

93. Loo C, Sheehan P, Pigot M, Lyndon W. A report on mood and cognitive outcomes with right unilateral ultrabrief pulsewidth $(0.3 \mathrm{~ms})$ ECT and retrospective comparison with standard pulsewidth right unilateral ECT. J Affect Disord 2007;103:277-281.

94. Baghai TC, Marcuse A, Brosch M, Schule C, Eser D, Nothdurfter C, et al. The influence of concomitant antidepressant medication on safety, tolerability and clinical effectiveness of electroconvulsive therapy. World J Biol Psychiatry 2006;7:82-90.

95. Singh A, Kar SK. How electroconvulsive therapy works?: understanding the neurobiological mechanisms. Clin Psychopharmacol Neurosci 2017;15:210-221. 